\title{
Kinetic Modelling of Drug Release from Pentoxifylline Matrix Tablets based on Hydrophilic, Lipophilic and Inert Polymers
}

${ }^{1}$ Department of Organic Chemistry, Faculty of Pharmacy, University of Medicine and Pharmacy, Tîrgu Mureș, Romania ${ }^{2}$ Department of Pharmaceutical Technology and Biopharmaceutics, Faculty of Pharmacy "Iuliu Haţieganu", University of Medicine and Pharmacy, Cluj-Napoca, Romania ${ }^{3}$ Department of Pharmaceutical Chemistry, Faculty of Pharmacy, University of Medicine and Pharmacy, Tîrgu Mureş, Romania

Abstract Pentoxifylline is a xanthine derivative used in the treatment of peripheral vascular disease, which because of its pharmacokinetic and pharmacologic profile is an ideal candidate for the development of extended release formulations. The aim of this study is to present a kinetic analysis of the pentoxifylline release from different extended release tablets formulations, using mechanistic and empirical kinetic models. A number of 28 formulations were prepared and analysed; the analysed formulations differed in the nature of the matrix forming polymers (hydrophilic, lipophilic, inert) and in their concentrations. Measurements were conducted in comparison with the reference product Trental $400 \mathrm{mg}$ (Aventis Pharma). The conditions for the dissolution study were according to official regulations of USP 36: apparatus no. 2, dissolution medium water, volume of dissolution medium is $1,000 \mathrm{~mL}$, rotation speed is $50 \mathrm{rpm}$, spectrophotometric assay at $274 \mathrm{~nm}$. Six mathematical models, five mechanistic (0 orders, $1^{\text {st }-o r d e r ~ r e l e a s e, ~ H i g u c h i, ~ H o p f e n b e r g, ~ H i x s o n-C r o w e l l) ~ a n d ~ o n e ~ e m p i r i c a l ~(P e p p a s), ~ w e r e ~ f i t t e d ~ t o ~ p e n t o x i f y l l i n e ~ d i s s o l u t i o n ~}$ profile from each pharmaceutical formulation. The representative model describing the kinetics of pentoxifylline release was the $1^{\text {st }}$-order release, and its characteristic parameters were calculated and analysed.

Keywords pentoxifylline-modified release tablets-polymers-kinetic modelling

\section{INTRODUCTION}

Pentoxifylline (PTX) (3,7-dimethyl-1-(5-oxohexyl)-3,7dihydro- $1 \mathrm{H}$-purine-2,6-dione) is a methylated xanthine derivative (Fig. 1) with vasodilatatory action, which improves the blood flow in the microcirculation, being particularly efficient in the post-stenotic ischemic areas. PTX is a competitive nonselective phosphodiesterase inhibitor, which raises intracellular cyclic adenosine monophosphate (cAMP) concentration, activates protein kinase A (PKA), inhibits leukotriene synthesis and reduces inflammation and innate immunity. In addition, PTX improves red blood cell deformability (known as a hemorrheologic effect), reduces blood viscosity and decreases the potential for platelet adhesion and aggregation and thrombus formation. PTX is also an antagonist at adenosine 2 receptors (Ward \& Clissold, 1987).

PTX is readily absorbed from the gastrointestinal tract but undergoes first-pass hepatic metabolism; some metabolites are active. The apparent plasma half-life of PTX is reported 
<smiles>CC(=O)CCCCN1C(=O)C2C(N=CN2C)N(C)C1=O</smiles>

Figure 1. Chemical structure of Pentoxifylline.

to be $0.4-0.8$ hours; that of the metabolites varies from 1.0 to 1.6 hours. In the treatment of peripheral vascular disease, the usual oral dose is $400 \mathrm{mg}$ three times daily in a modifiedrelease formulation; this may be reduced to $400 \mathrm{mg}$ twice daily for maintenance or if adverse effects are troublesome. Doses should be taken with meals to reduce gastrointestinal disturbances. The pharmacological profile of PTX and its short half-life make this drug a prime candidate for extended release formulations (Martindale, 2011).

By varying the concentration and nature of the hydrophilic, lipophilic and inert matrix forming polymers, we prepared 28 formulations, each obtained extended release tablet containing $400 \mathrm{mg}$ of PTX.

Using model-dependent methods to compare dissolution profiles requires the identification of a mathematical model that accurately describes the dissolution profile experimentally obtained and the statistical comparison of parameters values of the model used for the studied formulations (Sathe et al., 1996).

The aim of the study is to characterize the prepared formulations from the point of view of PTX release kinetic using model-dependent models.

\section{EXPERIMENTAL PART}

\section{Materials}

The materials used in this study were pentoxifylline (PTX) (Merck, Germany); hydroxypropylmethylcellulose (HPMC) - Methocel K4M Premium EP (Colorcon, UK); hydroxyethylcellulose (HEC) - Natrosol 250M (Aqualon Hercules, USA); hydroxypropylcellulose (HPC) - Klucel EXF (Aqualon Hercules, USA); Precirol AT 05 (Gattefossé S.A., France); Eudragit RS PO (Degussa, Germany); Eudragit RL PO (Degussa, Germany); Eudragit S100 (Degussa, Germany); Eudragit L100-55 (Degussa, Germany); Eudragit RS 30D (Degussa, Germany); polyethyleneglycol (PEG 6000) (Merck, Germany); ethylcellulose 45 cPs (EC) (BDH Chemicals Ltd., UK); magnesium stearate (Faci Spa., Italy); colloidal silicon dioxide (Aerosil 200) (Degussa, Germany); talcum (S\&D Chemicals, UK); lactose (Meggle, Germany); Compritol 888 AT0 (Gattefossé S.A., France); Emcompress (Penwest, UK). All materials used were of analytical grade.

\section{Apparatus}

AB 54S balance (Mettler-Toledo, Switzerland), analytical balance (Sartorius, Switzerland), mixer/stirrer (UMC 12. Stephan Hameln), oscillating granulator (Erweka $\mathrm{GmbH}$, Germany), tablet machine with eccentric (Korsch EKO, Germany), Hanson Research dissolution Tester SR 8+ (Hanson, USA), Shimadzu UV-1650 PC spectrophotometer (Shimadzu, Japan).

\section{Preparation of modified release tablets}

Formulations of the tablets based on hydrophilic matrix Extended release tablets containing PTX incorporated in hydrophilic matrices with different composition and concentration of hydrophilic polymers were obtained by wet granulation process, followed by the compression of the dry granules. The homogenised mixture of PTX with the hydrophilic matrix forming polymer (HPMC, HPC, HEC) was wet granulated in the mixer with a $5 \%$ aqueous solution of PEG 6000 (formulations F1-F8) and with a 4\% alcohol solution of ethylcellulose (formulations F9-F16), in a oscillating granulator. After drying the granules to a constant weight in a desiccator, magnesium stearate, aerosil, talcum (lubricants) and lactose (diluent) were added. The homogenised mixture was compressed through a compression procedure by an eccentric compression machine (Korsch) with one ponson with a diameter of $13 \mathrm{~mm}$ using the same compression pressure $(30 \mathrm{~N})$ for all formulations.

\section{Formulations of the tablets based on lipophilic matrix}

Extended release tablets containing PTX incorporated in lipophilic matrices with different concentration of the used lipophilic polymer (Precirol AT 05) were obtained by granulation process followed by the compression of the granules (formulations F17-F21). To highlight the lipid excipient's capacity to form lipophilic matrices using the given concentrations, we also prepared in parallel a control formulation without Precirol (formulation F22). The amount of Compritol that was incorporated in each formulation was maintained constant, because in the used concentration, the excipient does not have the capacity to form lipophilic matrices. For each formulation, the same method of preparation was applied. The lipophilic matrix for granulation was obtained by melting the lipid excipient at $60 \pm 2^{\circ} \mathrm{C}$ (maintaining a constant temperature in the granulator). In the mass obtained after the melting process, PTX was incorporated (by suspension, in the mixer/blender). The homogenised mass that was solidified at room temperature was afterwards granulated (in a granulator). The obtained granulates were mixed with Compritol 888 AT0 and lactose (with lubricant and diluent roles). The homogenised mixture was compressed. A compression procedure by an eccentric compression machine (Korsch) was used, with one ponson with a diameter 
of $13 \mathrm{~mm}$, using the same compression pressure $(30 \mathrm{~N})$ for all formulations.

\section{Formulations of the tablets based on inert matrix}

Extended release tablets containing PTX incorporated in inert matrices with Eudragit L100-55, Eudragit S100, Eudragit RS PO and Eudragit RL PO (formulations F23-F26), with different concentration of the used polymers, were obtained by a direct compression process. For each formulation, the same preparation method was applied. The blended mixture of powder excipients was mixed in the homogeniser and compressed. A compression procedure by an eccentric compression machine (Korsch) was used, with one ponson with a diameter of $13 \mathrm{~mm}$, using the same compression pressure $(30 \mathrm{~N})$ for all formulations.

Extended release tablets containing PTX incorporated in inert matrices with Eudragit RS 30D (formulations F27 and F28) were obtained by wet granulation process followed by the compression of the dry granules. The homogenised mixture of PTX with Emcompress diluent in the mixer/blender was wet granulated with an aqueous dispersion of Eudragit RS $30 \mathrm{D}$, in an oscillating granulator. After drying the granules to a constant weight in a desiccator, magnesium stearate and talcum (lubricants) were added. The homogenised mixture was compressed through a compression procedure by an eccentric compression machine (Korsch EKO, Germany), with one ponson with a diameter of $13 \mathrm{~mm}$ using the same compression pressure $(30 \mathrm{~N})$ for all formulations.

Each tablet contained $400 \mathrm{mg}$ of PTX. Table 1 displays the formulations of experimental design.

\section{Dissolution test}

The study of the obtained formulations was performed in comparison with the reference product, Trental 400.

In vitro dissolution test was conducted in accordance with the USP 36 stipulations (USP 36, 2014); the number 2 device (with paddles) was used; as dissolution medium, we used 1,000 mL of distilled water, maintained at a constant temperature of 37 $\pm 0.5^{\circ} \mathrm{C}$. In all experiments, the rotation speed used was 50 rpm. The measurements were performed on six tablets from each formulation studied $(n=6)$.

For the determination of the PTX released from the pharmaceutical formulations, in each experiment, $0.2 \mathrm{~mL}$ of sample were collected every 20,30 and 60 minutes within the first hour; every 30 minutes during the next three hours and every hour afterwards. The test was conducted for eight hours. The collected volume was replaced with an equivalent volume of distilled water in order to maintain a constant volume of the dissolution medium. The collected samples $(0.2$ $\mathrm{mL}$ ) were diluted with distilled water to $10 \mathrm{~mL}$.

PTX was determined by UV spectrophotometric analysis, at $274 \mathrm{~nm}$ against a blank of distilled water. At each collecting time, the cumulative percentage of released drug was calculated.

\section{Selecting of the mathematical model of analysis}

The determination of in vitro release kinetics of the drug first entails the identification of a mathematical model that accurately describes the experimental data. The selection criteria commonly used are the Akaike or Schwarz criteria (Kohler \& Murphree, 1998; Ludden, 1994). These indices represent a statistical test that considers the accuracy of the fitting (the sum of squared differences between the experimental value and the one predicted by the model) and the number of parameters that are characteristic to the model. A lower value for these indices is correlated with a better fitting. The individual dissolution curves of the drug are fitted by using mathematical models. On the basis of the average/ mean values of the Akaike index, the mathematical model that describes the dissolution profile for all formulations analysed most accurately is subsequently selected. The quantitative interpretation of the values obtained after the dissolution test is easier/simpler by using mathematical equations that describe the release profile according to some parameters related to the pharmaceutical formulation (van Vooren, 2001). The individual dissolution curves of PTX from the formulated matrices were fitted by using six mathematical models, five of which were mechanistic models ( 0 order release, $1^{\text {st }}$-order release, Higuchi, Hopfenberg, Hixson-Crowell) and the other one was an empirical method (Peppas) (Costa \& Lobo, 2001)

(Table 2). From the commonly used selection criteria (Akaike, Schwartz, residual analysis), the Akaike criteria was chosen to discriminate between competing models (in which a lower value of the parameter indicates a better fitting). The fitting method was a linear or non-linear regression, and it was performed by using the WinNonlin software. On the basis of the values of the Akaike index, the mathematical model that describes the dissolution profile for all formulations analysed most accurately was afterwards selected (Ramteke et al., 2014).

The representative model describing the kinetics of PTX release was $1^{\text {st }}$-order release and its characteristic parameters were calculated and analysed.

\section{RESULTS AND DISCUSSION}

The release profiles ( $n=6$ ) of PTX from the studied formulations in comparison with the reference product (Trental, $400 \mathrm{mg}$ ) are presented in Fig. 2

After the individual fitting of the dissolution profiles of PTX from the studied formulations, for each dissolution profile, the Akaike values (average) were compared, related to the model by which the fitting was accomplished. The individual and average/mean Akaike values for each kinetic model used are presented/shown in Fig. $\mathbf{3}$ and Table $\mathbf{3}$.

In Table 3, the minimum Akaike values are marked in bold. As it can be seen, the $1^{\text {st }}$-order release mechanistic model best characterized the observed data (the minimum Akaike values), and it has been chosen as a reference model for 


\begin{tabular}{|c|c|c|c|c|c|c|c|c|c|c|c|c|c|c|c|c|c|c|c|c|c|c|c|c|c|c|c|c|}
\hline 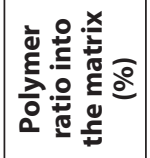 & $\stackrel{+}{m}$ & $\stackrel{+}{m}$ & นด & $\bar{m}$ & $\therefore$ & 垨 & $\approx$ & $\dot{m}$ & $\approx$ & $\stackrel{+}{m}$ & $\stackrel{\llcorner}{\sigma}$ & ষ্ & $\bar{m}$ & 年 & $\dot{m}$ & $\approx$ & 으 & $\stackrel{\ln }{\sim}$ & ㄱ & $\stackrel{\llcorner}{\sim}$ & ○ & 0 & 으 & 으 & 으 & 으 & 으 & \\
\hline Џ્ટુ & $\stackrel{0}{\stackrel{2}{\leftarrow}}$ & in & $\stackrel{0}{-}$ & $\underset{\mathrm{n}}{\stackrel{N}{m}}$ & $\begin{array}{l}\infty \\
\infty \\
\dot{J} \\
\dot{J}\end{array}$ & $\stackrel{\text { f }}{\mathrm{i}}$ & 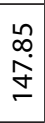 & $\underline{m}$ & $\stackrel{\infty}{+}$ & $\begin{array}{l}\underset{+}{\infty} \\
\check{E}\end{array}$ & 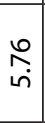 & $\begin{array}{l}0 \\
\text { ம }\end{array}$ & ָָ & . & $\begin{array}{l}\infty \\
\stackrel{\sim}{*}\end{array}$ & J & 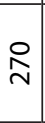 & 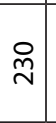 & ஃ & $\stackrel{\text { 윰 }}{n}$ & 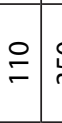 & 윯 & ' & ' & 1 & 1 & 1 & \\
\hline 돌 & $\stackrel{\searrow}{\sim}$ & $\stackrel{d}{\sim}$ & $\stackrel{\searrow}{\sim}$ & $\stackrel{ \pm}{\sim}$ & $\stackrel{\searrow}{\sim}$ & $\stackrel{ \pm}{\sim}$ & $\stackrel{ \pm}{\sim}$ & $\stackrel{\searrow}{\sim}$ & $\stackrel{ \pm}{\sim}$ & $\stackrel{\searrow}{\sim}$ & $\stackrel{\searrow}{\sim}$ & $\stackrel{\searrow}{\sim}$ & $\stackrel{\searrow}{\sim}$ & $\stackrel{+}{ \pm}$ & $\stackrel{\Xi}{\sim}$ & $\stackrel{\Xi}{\sim}$ & I & ' & I & ' & I & & $\stackrel{\searrow}{\sim}$ & $\stackrel{ \pm}{\sim}$ & $\stackrel{\Xi}{\sim}$ & $\stackrel{\sim}{\sim}$ & $\stackrel{ \pm}{\sim}$ & $\stackrel{\searrow}{\sim}$ \\
\hline 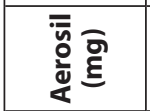 & $\infty$ & $\infty$ & 1 & $\infty$ & $\infty$ & 1 & $\infty$ & $\infty$ & $\infty$ & $\infty$ & 1 & ০ & $\infty$ & 1 & 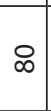 & $\infty$ & 1 & 1 & ' & ' & I & 1 & ' & I & ' & I & 1 & \\
\hline 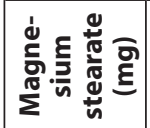 & $\infty$ & $\infty$ & $\infty$ & $\infty$ & $\infty$ & $\infty$ & $\infty$ & $\infty$ & $\infty$ & $\infty$ & $\infty$ & $\infty$ & $\infty$ & $\infty$ & $\infty$ & $\infty$ & 1 & I & ' & I & I & I & $\infty$ & $\infty$ & $\infty$ & $\infty$ & $\infty$ & $\infty$ \\
\hline 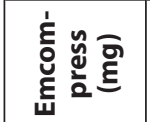 & 1 & ' & I & 1 & 1 & ' & ' & 1 & ' & I & 1 & 1 & I & 1 & ' & ' & 1 & ' & ' & ' & I & 1 & $\stackrel{\infty}{\sim}$ & $\begin{array}{l}\infty \\
\stackrel{\infty}{\sim}\end{array}$ & $\begin{array}{l}\infty \\
\stackrel{\infty}{\sim}\end{array}$ & $\begin{array}{l}\infty \\
\stackrel{\infty}{\sim}\end{array}$ & $\begin{array}{l}\infty \\
\stackrel{\infty}{\sim}\end{array}$ & $\stackrel{\infty}{\circ}$ \\
\hline
\end{tabular}

\begin{tabular}{|c|c|c|c|c|c|c|c|c|c|c|c|c|c|c|c|c|c|c|c|c|c|c|c|c|c|c|c|}
\hline 这 을 & I & 1 & ' & ' & ' & ' & I & ' & ' & I & ' & ' & ' & 1 & ' & ' & 유 & 음 & 유 & 유 & 유 & 은 & ' & ' & ' & 1 & \\
\hline પ & I & ' & I & 1 & 1 & I & I & I & $\nabla$ & $\frac{6}{\dot{\tau}}$ & $\underset{\sim}{\mathbb{N}}$ & $\stackrel{+}{\circ}$ & $\begin{array}{l}\infty \\
\stackrel{i}{i}\end{array}$ & $\stackrel{0}{\stackrel{0}{1}}$ & $\stackrel{N}{=}$ & $\infty$ & 1 & ' & I & ' & ' & ' & ' & ' & ' & 1 & \\
\hline 능용 흐 & 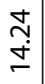 & $=$ & $\stackrel{\nabla}{\circ}$ & $\stackrel{\infty}{\sim}$ & $\stackrel{2}{\check{r}}$ & $\stackrel{n}{n}$ & $\stackrel{\stackrel{n}{\leftarrow}}{\dot{\sim}}$ & $m$ & ' & 1 & ' & I & 1 & ' & ' & ' & 1 & 1 & ' & ' & ' & I & ' & ' & ' & ' & \\
\hline 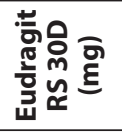 & 1 & ' & ' & 1 & 1 & ' & I & I & ' & I & I & ' & I & ' & ' & ' & 1 & ' & ' & ' & ' & I & ' & ' & ' & 1 & 8 \\
\hline 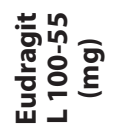 & 1 & ' & 1 & 1 & 1 & 1 & 1 & ' & ' & ' & ' & ' & I & 1 & ' & ' & 1 & ' & I & ' & ' & I & ' & ' & I & $\infty$ & \\
\hline
\end{tabular}

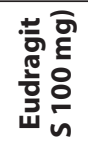

훙응 응

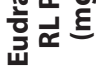

\begin{tabular}{|c|c|c|c|c|c|c|c|c|c|c|c|c|c|c|c|c|c|c|c|c|c|c|c|}
\hline 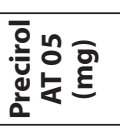 & & & & ' & ' & & & & & & ' & & & $\delta$ & $\stackrel{\mathcal{I}}{\stackrel{I}{*}}$ & $\stackrel{\circ}{\circ}$ & 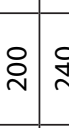 & & & & & & \\
\hline 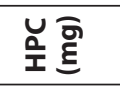 & & & & & $\stackrel{\circ}{\circ}$ & $\mid \begin{array}{l}0 \\
- \\
\end{array}$ & $\underset{\sim}{\sim}$ & $\stackrel{m}{m}$ & $\begin{array}{c}\mathbf{v} \\
v\end{array}$ & & & & & & 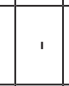 & & & & & & & & \\
\hline 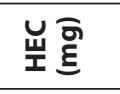 & N & & & 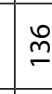 & & & & & & & & & & & t & & & & 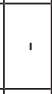 & & & & \\
\hline 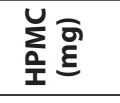 & & $\stackrel{\approx}{\approx}$ & 8 & & & & & & & & $\stackrel{\infty}{\stackrel{D}{N}}$ & & & &, & & & & ' & & & & \\
\hline 可 & $f$ & ষ্ণ & o & q & ষ্ণ & 条 & প্ণ & $\stackrel{8}{8}$ & g & প্ণ & 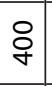 & $f$ & & ơ & : & প্ণে & $\begin{array}{l} \\
\dot{q}\end{array}$ & 8 & 吕 & প্ণ & & & \\
\hline 4 & - & & 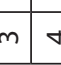 & in & 0 & & $\infty$ & & $2=$ & $\simeq$ & $\stackrel{m}{-}$ & \pm & & 0 ? & 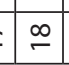 & & & & & & & & \\
\hline
\end{tabular}


Table 2. Kinetic models used for the profile analysis of PTX release from modified tablets

\begin{tabular}{|c|c|c|c|}
\hline Model & Kinetic model & Parameters & Equation \\
\hline M1 & 0 order & $\mathrm{t}_{\text {ced }}\left(\mathrm{k}_{\text {ced }}\right)$ & \% dissolved $=\mathrm{kt}$ \\
\hline $\mathrm{M} 2$ & $1^{\text {st }}$ order & $\mathrm{k}_{1}$ & \% dissolved $=100\left(1-\mathrm{e}^{-\mathrm{kt}}\right)$ \\
\hline $\mathrm{M} 3$ & Higuchi & $\mathrm{k}_{\mathrm{Hg}}$ & \% dissolved $=\mathrm{k}(\mathrm{t})^{0.5}$ \\
\hline M4 & Hopfenberg $\mathrm{n}=2$ & $\mathrm{~K}$ & \% dissolved $=100(1-(1-\mathrm{kt}))^{\mathrm{n}} ; \mathrm{n}=1.2 .3$ \\
\hline M5 & Hixson-Crowell & $\mathrm{K}$ & \% dissolved $=100\left[1-(1-\mathrm{kt} / 4.6416)^{3}\right]$ \\
\hline M6 & Peppas & $\mathrm{k}_{\mathrm{Pe}} \cdot \mathrm{n}$ & $\mathrm{k}(\mathrm{t})^{\mathrm{n}}$ \\
\hline
\end{tabular}

( $k$ is the release rate constant, $n$ the apparent grade of the dissolution process (the Peppas and Hopfenberg models) and $t$ the time.)

Table 3. The individual and average/mean values of the Akaike indices calculated for each formulation studied in fitting the chosen models

\begin{tabular}{|c|c|c|c|c|c|c|}
\hline Formulation & 0 order release & $\begin{array}{l}1^{\text {st }} \text {-order } \\
\text { release }\end{array}$ & Higuchi & $\begin{array}{c}\text { Hopfenberg } \\
n=2\end{array}$ & $\begin{array}{l}\text { Hixson- } \\
\text { Crowell }\end{array}$ & Peppas \\
\hline $\mathrm{Fr}$ & 65.0 & 44.4 & 65.0 & 51.3 & 47.0 & 52.7 \\
\hline F1 & 76.2 & 56.8 & 69.5 & 53.3 & 51.4 & 70.5 \\
\hline $\mathrm{F} 2$ & 80.8 & 60.6 & 71.6 & 52.6 & 53.9 & 72.8 \\
\hline $\mathrm{F} 3$ & 80.2 & 57.0 & 70.3 & 54.2 & 53.1 & 76.2 \\
\hline $\mathrm{F} 4$ & 77.6 & 56.0 & 69.0 & 51.4 & 49.4 & 86.1 \\
\hline F5 & 74.7 & 56.7 & 69.8 & 55.0 & 52.9 & 68.1 \\
\hline F6 & 64.7 & 45.0 & 64.7 & 51.3 & 47.3 & 51.8 \\
\hline F7 & 70.5 & 49.5 & 65.3 & 57.3 & 53.2 & 59.1 \\
\hline F8 & 68.6 & 47.0 & 65.2 & 52.9 & 48.3 & 55.3 \\
\hline F9 & 64.9 & 58.8 & 68.9 & 54.7 & 55.0 & 55.0 \\
\hline $\mathrm{F} 10$ & 64.0 & 56.6 & 69.6 & 48.3 & 49.6 & 52.8 \\
\hline F11 & 66.9 & 56.1 & 67.8 & 53.8 & 52.8 & 55.0 \\
\hline F12 & 80.4 & 58.1 & 70.9 & 54.8 & 54.0 & 76.7 \\
\hline F13 & 67.0 & 48.6 & 66.3 & 53.4 & 49.7 & 56.1 \\
\hline F14 & 68.3 & 46.4 & 65.3 & 54.0 & 49.5 & 56.1 \\
\hline F15 & 79.0 & 51.0 & 59.0 & 62.1 & 57.6 & 72.5 \\
\hline F16 & 67.0 & 46.6 & 65.6 & 52.8 & 48.6 & 54.9 \\
\hline F17 & 73.3 & 52.8 & 63.7 & 63.0 & 59.4 & 62.3 \\
\hline F18 & 73.0 & 52.0 & 60.9 & 63.3 & 59.6 & 59.8 \\
\hline F19 & 72.1 & 48.8 & 60.8 & 61.6 & 57.5 & 58.2 \\
\hline $\mathrm{F} 20$ & 68.5 & 45.9 & 63.0 & 57.2 & 53.0 & 56.2 \\
\hline F21 & 64.1 & 46.6 & 64.0 & 52.8 & 49.4 & 52.0 \\
\hline $\mathrm{F} 22$ & 102.1 & 16.3 & 39.4 & 93.0 & 84.9 & 103.8 \\
\hline $\mathrm{F} 23$ & 66.6 & 42.3 & 64.5 & 52.1 & 46.9 & 53.5 \\
\hline $\mathrm{F} 24$ & 79.0 & 58.5 & 70.5 & 56.2 & 54.9 & 89.5 \\
\hline $\mathrm{F} 25$ & 69.1 & 42.1 & 63.0 & 55.7 & 50.5 & 55.0 \\
\hline $\mathrm{F} 26$ & 76.3 & 58.3 & 70.1 & 53.9 & 53.0 & 88.8 \\
\hline $\mathrm{F} 27$ & 77.6 & 55.1 & 68.3 & 56.4 & 53.0 & 72.2 \\
\hline F28 & 71.5 & 51.5 & 63.6 & 60.4 & 56.8 & 59.5 \\
\hline Average & 71.5 & 51.5 & 65.3 & 54.2 & 53.0 & 59.1 \\
\hline
\end{tabular}




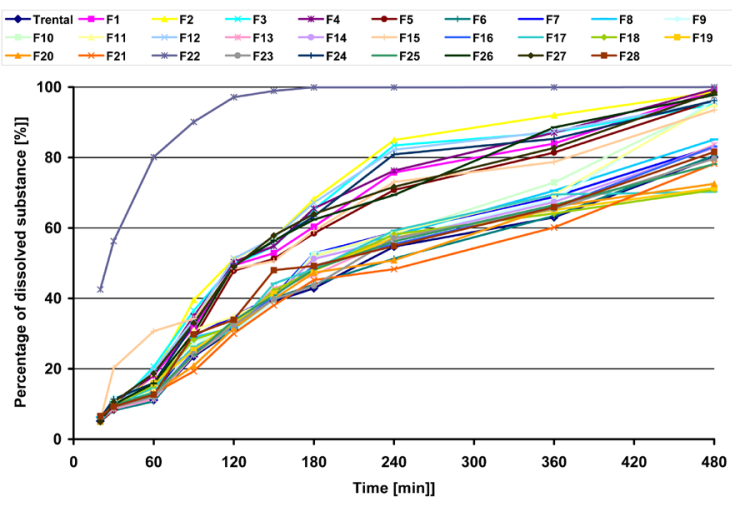

Figure 2. PTX dissolution profiles for the examined formulations.

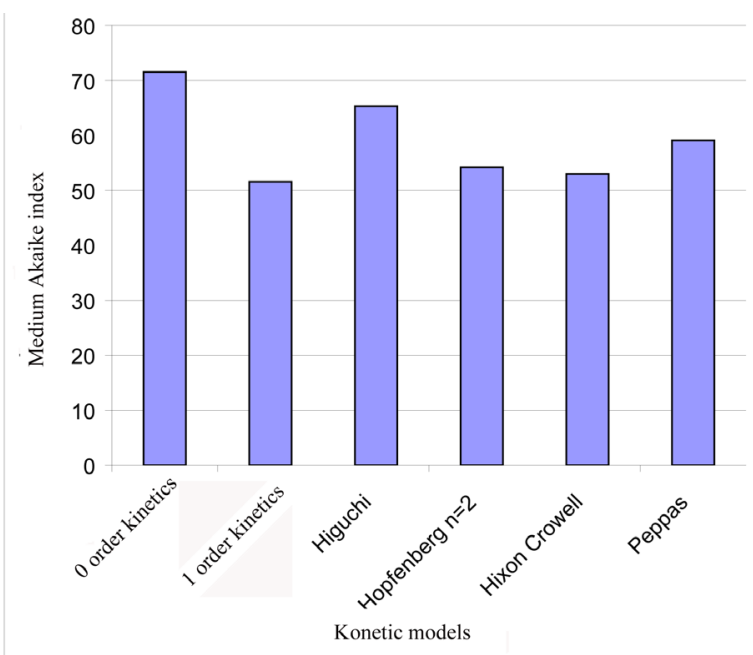

Figure 3. The average/mean values of Akaike indices calculated for each formulation studied after fitting the chosen models.

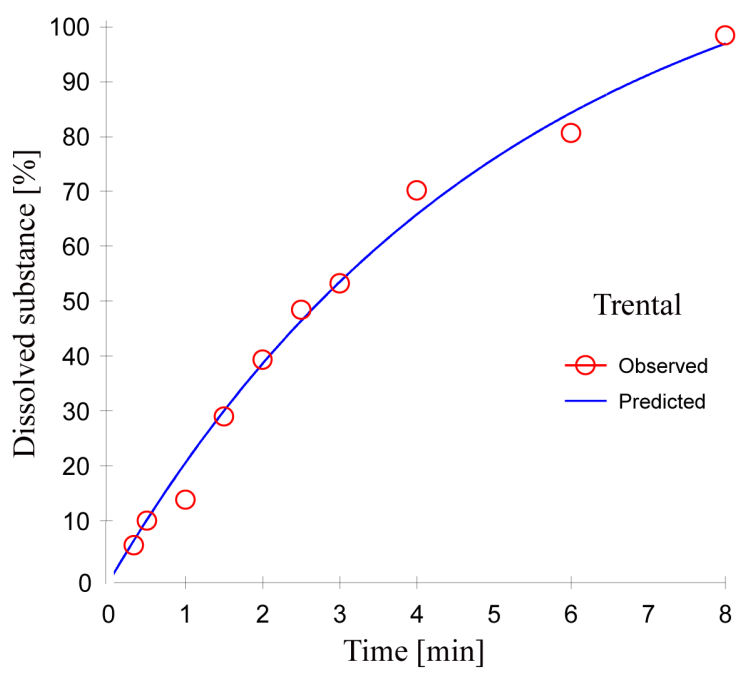

Figure 4. 1st order release kinetic model fitting for the reference product, Trental $400 \mathrm{mg}$. subsequent calculations. The $1^{\text {st }}$-order release kinetic model is characterised by the release constant $k$, a parameter that characterised the in vitro release process of PTX.

By analysing the obtained data, it can be seen that from the mechanistic models, the one that fitted best the experimental data is the model with the $1^{\text {st }}$-order release kinetics (with the lowest median and it optimally fitted 17 formulations); the Hopfenberg model optimally fitted three formulations, and the Hixson-Crowell model optimally fitted nine formulations. According to these data, it can be concluded that in terms of the release mechanism, the majority of the analysed formulations have a $1^{\text {st }}$-order release kinetics (the release rate depends proportional on the fraction of undissolved substance), because even in the cases where the $1^{\text {st }}$-order release kinetics was not the optimal model, the visual examination of fitting the dissolution profile with the $1^{\text {st }}$-order release kinetics shows a good correspondence between the experimental data and this mathematical model. Therefore, the $1^{\text {st }}$-order kinetic model was chosen as a representative model for all formulations studied. Figures 4-7 shows the fitting of the optimal mechanistic model for some of the analysed formulations.

The specific kinetic parameters for the mechanistic model chosen for each product are presented in Table 4. In the $1^{\text {st }}$ order kinetic process, the constant has the unit $\mathrm{min}^{-1}$.

By analysing the obtained kinetic parameters, it can be observed that the values of the speed constants of the releasing process for each formulation and for the reference product (Trental $400 \mathrm{mg}$ ) fall between the limits $\mathrm{k}=0.1738$ 0.3560 and the corresponding half-lives between the limits $t_{1 / 2}=1.95-3.99$. Half-life values close to those of the reference product (Trental, $t_{1 / 2}=3.75$ ) were obtained for the following formulations: F6 (with 45\% HPC granulated with PEG 6000, $t_{1 / 2}=3.76$ ), F13 (with 31\% HPMC granulated with ethylcellulose, $t_{1 / 2}=3.47$ ), $F 14$ (with 45\% HPMC granulated with ethylcellulose, $\mathrm{t}_{1 / 2}=3.38$ ), $\mathrm{F} 16$ (with $17 \%$ HEC granulated with ethylcellulose, $t_{1 / 2}=3.47$ ), $F 17$ (with 10\% Precirol AT 05, $\mathrm{t}_{1 / 2}=3.48$ ), $\mathrm{F} 18$ (with 15\% Precirol AT 05, $\mathrm{t}_{1 / 2}=3.58$ ), F19 (with $20 \%$ Precirol AT 05, $\mathrm{t}_{1 / 2}=3.60$ ), F20 (with $25 \%$ Precirol AT $05, \mathrm{t}_{1 / 2}=3.82$ ), $\mathrm{F} 21$ (with $30 \%$ Precirol AT 05, $\mathrm{t}_{1 / 2}=3.99$ ), F23 (with 10\% Eudragit RS PO, $\mathrm{t}_{1 / 2}=3.61$ ), F25 (with 10\% Eudragit $\mathrm{S} 100, \mathrm{t}_{1 / 2}=3.51$ ) and $\mathrm{F} 28$ (with $20 \%$ Eudragit RS 30D, $\mathrm{t}_{1 / 2}=$ 3.31). Regarding formulation F22, a comparison formulation, the obtained kinetic parameters, $k=1.6430$ and $t_{1 / 2}=0.42$, indicate an inadequate release kinetics; the formulation does not contain Precirol AT 05, a lipophilic matrix forming excipient, and the quantity of Compritol incorporated is insufficient to form a lipophilic matrix and to ensure an extended release.

From comparative analysis of dissolution profiles of PTX from the proposed formulations and from the industrial reference product (Trental, $400 \mathrm{mg}$ ) and also based on the values of the obtained kinetic parameters, it can be concluded that from the 28 formulations made from hydrophilic, lipophilic and plastic matrices, formulation F6, with 45\% HPC granulated 


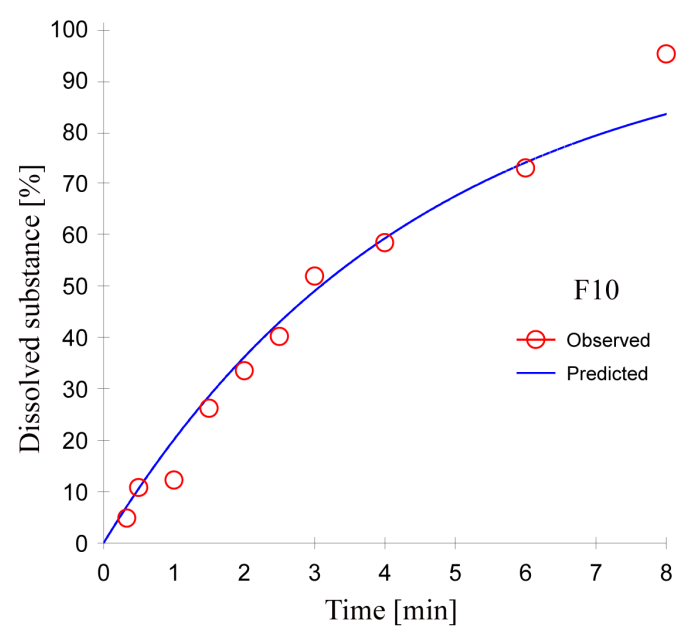

Figure 5. 1st order release kinetic model fitting for formulation F10 (with 34\% HPC granulated with ethyl cellulose).

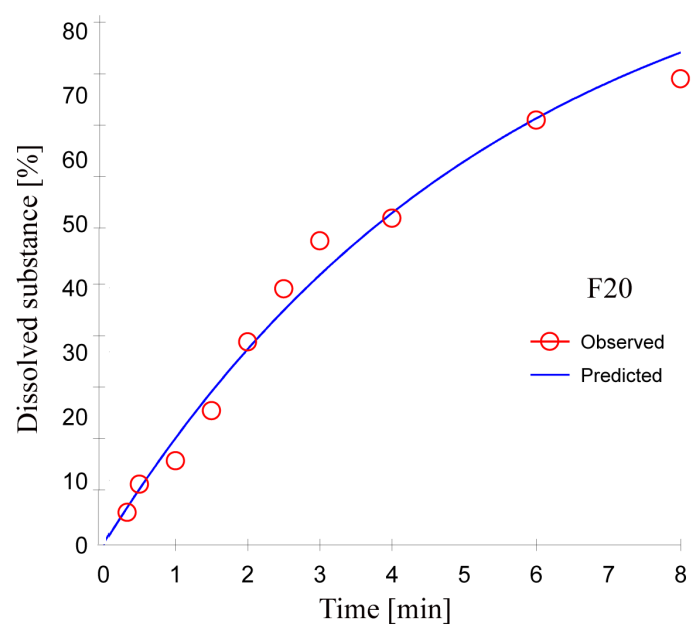

Figure 6. 1st order release kinetic model fitting for formulation F10 (with 25\% Precirol AT05).

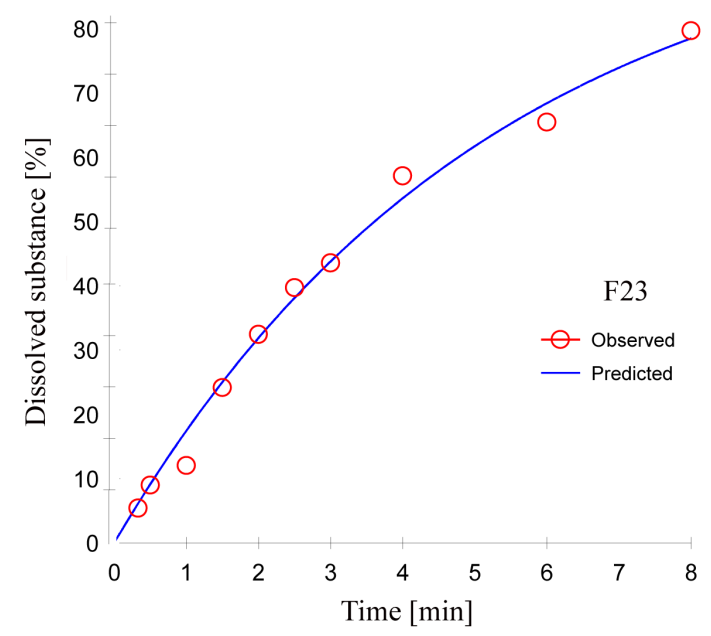

Figure 7. 1st order release kinetic model fitting for formulation F23 (with 10\% Eudragit RS PO).
Table 4. Specific kinetic parameters for $1^{\text {st }}$-order kinetic model

\begin{tabular}{|c|c|c|c|}
\hline Formulation & $\begin{array}{c}\text { Value } \\
\left(\text { hour }^{-1} \text { ) }\right.\end{array}$ & $\begin{array}{c}\text { CV of } \\
\text { determination's } \\
\text { error }\end{array}$ & $\begin{array}{l}t_{1 / 2} \text { of } \\
\text { release } \\
\text { (hour) }\end{array}$ \\
\hline $\mathrm{Fr}$ & 0.1849 & 3.3 & 3.75 \\
\hline F1 & 0.3062 & 5.8 & 2.26 \\
\hline $\mathrm{F} 2$ & 0.3560 & 7.0 & 1.95 \\
\hline F3 & 0.3346 & 5.9 & 2.07 \\
\hline $\mathrm{F} 4$ & 0.3230 & 5.6 & 2.15 \\
\hline F5 & 0.2834 & 5.8 & 2.44 \\
\hline F6 & 0.1844 & 3.4 & 3.76 \\
\hline F7 & 0.2145 & 4.2 & 3.23 \\
\hline F8 & 0.2148 & 3.7 & 3.23 \\
\hline F9 & 0.2197 & 6.6 & 3.15 \\
\hline F10 & 0.2244 & 5.9 & 3.09 \\
\hline F11 & 0.2269 & 5.7 & 3.05 \\
\hline F12 & 0.3384 & 6.2 & 2.05 \\
\hline F13 & 0.1995 & 4.0 & 3.47 \\
\hline F14 & 0.2049 & 3.6 & 3.38 \\
\hline F15 & 0.3057 & 4.4 & 2.27 \\
\hline F16 & 0.1996 & 3.7 & 3.47 \\
\hline F17 & 0.1993 & 5.0 & 3.48 \\
\hline F18 & 0.1934 & 4.8 & 3.58 \\
\hline F19 & 0.1924 & 4.1 & 3.60 \\
\hline F20 & 0.1815 & 3.6 & 3.82 \\
\hline $\mathrm{F} 21$ & 0.1738 & 3.8 & 3.99 \\
\hline F22 & 1.6430 & 1.1 & 0.42 \\
\hline F23 & 0.1920 & 3.0 & 3.61 \\
\hline $\mathrm{F} 24$ & 0.3216 & 6.3 & 2.15 \\
\hline F25 & 0.1974 & 2.9 & 3.51 \\
\hline F26 & 0.3061 & 6.3 & 2.26 \\
\hline $\mathrm{F} 27$ & 0.3127 & 5.3 & 2.22 \\
\hline F28 & 0.2092 & 4.6 & 3.31 \\
\hline
\end{tabular}

with PEG 6000 presents a dissolution profile close to that of Trental and values of the kinetic parameters very similar to those of Trental.

\section{CONCLUSIONS}

Six kinetic models were tested, five mechanistic (0 order release, $1^{\text {st }}$-order release, Higuchi, Hopfenberg, HixsonCrowell) and an empirical one (Peppas).

As it can be seen from the obtained data, the optimal kinetic model is the $1^{\text {st }}$-order release, this model being selected as the one that best describes the experimental data. For this type of kinetics, parameters $k$ and half-life $t_{1 / 2}$ were calculated. This model fitted best the experimental data (with the lowest average and optimally fits 17 formulations). 


\section{Kinetic Modelling of Drug Release from Pentoxifylline Matrix Tablets based...}

According to these data, it can be said that regarding the releasing mechanism, the majority of the analysed formulations have a $1^{\text {st }}$-order kinetics (the release rate depends proportional on the fraction of undissolved substance).

From the proposed formulations, F6 with 45\% HPC granulated with PEG 6000 presents a dissolution profile close to that of Trental and values of the kinetic parameters very similar to those of Trental $\left(k=0.1844\right.$ and $\left.t_{1 / 2}=3.76\right)$.

\section{References}

[1] Costa P, Lobo JMS. Modelling and comparison of dissolution profiles. Eur J Pharm Sci. 2001;13:123-133.

[2] Kohler AN, Murphree ES. A comparison of the Akaike and Schwarz criteria for selecting model order. Appl Statist. 1998;37:187-195.

[3] Ludden TM, Beal SL, Sheiner LB. Comparison of the Akaike Information Criterion, the Schwarz criterion and the $F$ test as guides to model selection. J. Pharmacokinetic Biopharm. 1994;22:431-445.

[4] Martindale, The Complete Drug Reference. $37^{\text {th }}$ ed. London, Pharmaceutical Press; 2011, 1367p.

[5] Ramteke KH, Dighe PA, Kharat AR, Patil SV. Mathematical models of drug dissolution: a review. Sch. Acad. J. Pharm. 2014;3:388-396.
[6] Sathe PM, Tsong Y, Shah VP. In-vitro dissolution profile comparison: statistics and analysis, model dependent approach. Pharm Res. 1996;13:1799-1803.

[7] The United States Pharmacopeia. $36^{\text {th }}$ ed. Rockwell: United States Pharmacopeial Convention, 2014.

[8] van Vooren L, Krikilion G, Rosier J, de Spiegelee B. A novel bending point criterion for dissolution profile interpretation. Drug Dev Ind Pharm. 2001;27:885-892.

[9] Ward A, Clissold SP. Pentoxifylline. A review of its pharmacodynamic and pharmacokinetic properties, and its therapeutic efficacy. Drugs 1987;34:50-97. 